considerable cost and with variable quality. Even if the locum is experienced, there is a fair chance that he will not have worked in your department, or hospital, before. It is better for quality of care if a list of former SHOs, local general practitioners, and interested others is maintained. This means more work for the business manager or staffing department in contacting them, but the result is much more acceptable. It is also worthwhile being generous. Allow the odd day to be added to a period of leave to make travelling easier. This can always be used as a lever when disaster strikes, and greatly reduces the amount of arm twisting necessary to fill a gap.

\section{The middle grades}

Here you may wish to relax. After a brief discussion with them, to agree the duration and level of cover required, the middle grade staff can gain valuable experience producing their own rota. Basic ground rules will define the number of middle grades who can be "away" at the same time, the arrangements for "research and study", the level of "front line work" and any other contentious points.

In departments with one or two consultants and small numbers of middle grades, it may be sensible to include everyone in a "senior doctors" rota, spreading the load more equitably. It is then important that middle grades do not always work with the same consultant. Variations on a theme are always useful. From the consultant's viewpoint, a final year specialist registrar should need less supervision than a first year.

\section{Solving consultant dilemmas?}

Most consultants agree that time spent supervising SHOs and discussing problems with middle grades is very valuable. Perhaps this part of the consultant's work should be allocated first. However, until personally experienced, it is difficult for trainees to imagine the sheer volume of paper which crosses the average consultant desk, and it is very easy for the busy clinical consultant to find himself still in the office at some ungodly hour at the expense of family, health, and sanity.

Fixing sessions is all too easy (and something that managers are keen on) but may be very difficult to fulfil when colleagues are absent. Our specialty is attractive to many of us because of the variety it provides, and by its very nature the demands on our time must vary if patients are to be well served. In my job plan (which contains only five fixed sessions) is the phrase:
"In recognition of the special circumstances which apply to Accident $\mathcal{E}$ Emergency work it is agreed that these fixed sessions may from time to time need to be worked flexibly throughout the week in order to ensure that they are achieved."

Some such phrase is recommended, especially if a lot of fixed sessions are expected.

Some things are, however, better fixed. Follow up clinics, minor operation lists, and special interest sessions are probably best done by the same person at the same time each week. In the interests of communication it is essential that all the seniors meet regularly once a week for an hour or two to discuss problems and policies so, for at least a brief period, no matter how complicated and flexible the rota, everyone should be in the same place at the same time.

When there is only one consultant, no one expects him to be there all the time. As numbers increase there is a disproportional expectation of consultant availability. You and your colleagues must agree how much time each of you will spend "at the front desk" and how (if at all) you will cover each other's sessions.

Inevitably, more managerial roles seem to creep up on all of us, indeed some even seek these tasks. The effect of these roles on your own time and on that of colleagues must be borne in mind. What are you going to give up to undertake this new role effectively? Beware of spreading yourself too thinly and not actually achieving any of the goals.

\section{And finally}

Planning a rota can be tedious and time consuming, but is nonetheless a positive challenge. Why not try something totally different? How about doctors and nurses working the same shifts?

In one $A \& E$ department, on an experimental basis, all the staff worked in teams led by a senior doctor. Doctors, nurses, radiographers, physio, plaster technician, receptionists, and even the secretary all worked the same rota. For three months the same people worked together on every shift. Team building at its best? It seemed to workbut for how long?

This brief article has probably raised more questions than it has answered but hopefully it has stimulated some thought. Rota solutions which work should be shared.

IAIN C GRANT

Accident and Emergency Department, Derriford Hospital, Plymouth

\section{How to find an SHO}

Although some hospitals may still be in the happy position of having at least one and possibly more applicants for every SHO post, the shortage of SHOs (particularly in $\mathrm{A} \& \mathrm{E}$ ) is now well known and before one can appoint, one must attract suitable applicants. I give a few ideas below. These should not be considered as a way of solving a crisis, as in the long run the methods one uses to attract good staff and the methods one employs to run a good department are identical.

It is important that the job offers good experience. This is not just experience of practical procedures; with the range of conditions seen in the department one of the most important skills to be learnt in A\&E is decision making. A department where SHOs are allowed to make decisions will be more attractive than one in which the decision to admit or discharge is always made after referral for a specialist opinion. Good support for SHOs in this decision making is essential. Consultants may argue about being resident on call, but for patients and SHOs there can be little doubt that 24 hour senior or middle grade cover in the department is the ideal. This is not always possible but one should aim for someone more senior than an SHO to be in the department for as many of the 168 hours a week as is possible, and SHOs should know where they can get help in the absence of more senior A\&E staff (for example, trauma team). Support should be more than nominal: a presence in the consulting room is much more valuable than advice over a phone. Sensible rotas are a must: all SHOs will appreciate that the department must be staffed continuously, but do not use them just to fill the difficult times that staff grade doctors won't work! Consider links with other departments to form rotations. 
Poor working conditions will put people off. If necessary, management must be fought to obtain improvements to the department, rest rooms, and so on. Use any influence you have to improve junior doctor accommodation, the doctor's mess, the catering, etc. Ensure good relationships with A\&E nursing staff and with other hospital departments.

SHOs are in training posts and it is important that they are taught well. Formal teaching is important and must be done in protected time with the department being covered by, for example, clinical assistants. Equally important is "bedside" teaching. Much learning in medicine comes from observing patient outcomes, but in A\&E there is a risk that one never hears what happens to the patients one treats. Encourage SHOs to follow patients up on the wards and ensure that they are given positive feedback and not just the negative feedback that comes when they make errors. Links with fracture clinic and obtaining discharge summaries of patients admitted may help. Encourage them to take study leave and try to ensure that local ALS or ATLS courses reserve places for your A\&E SHOs. A good boss can make all the difference to any job and you may need to improve your own performance. If necessary take advantage of courses on teaching methods, appraisal skills, and so on.

Ensure that the pay is right and that the ADHs paid reflect the fact that SHOs are expected to come to teaching sessions on their days off and may have late finishes as they stay on to sort out a difficult problem or to visit a ward to find out what happened to their patient.
There is no point having a perfect job if people do not know about it! Your best advertisement is your present and past SHOs, who will spread the word up and down the land, so treat them well. Try to attract medical students to your department, either on formal attachments or on electives-they may wish to return when qualified. Take every opportunity to teach house officers and medical students. Talk to them when they come into the department and encourage them to apply for your job. Advertise early while the pool of potential SHOs is still large. If you do get more suitable applicants than posts then, at interview, unsuccessful applicants can be offered a job for six months later.

The job will need to be formally advertised as well. There is a balance to be drawn between attracting attention with an interesting advertisement and putting people off with something too blatant ("what is the matter with the place if they have to advertise like that").

Once people have been attracted by the advertisement they will write for a job description. This is an official document with legal importance, but ensure that it shows the department in as good a light as possible. The hospital will probably also have promotional literature to send out to attract staff. Ensure that this is appropriate and well produced. In addition to the official job description, a prospectus to explain the way the department works and the experience that can be gained is also valuable .

H R GULY

Accident and Emergency Department, Derriford Hospital, Plymouth

\section{The management series}

The articles in the management series deal with common management issues faced by A\&E consultants. The authors are practising $A \& E$ consultants and a media specialist who have provided their way of addressing these issues. It is hoped that this series will contribute to the discussion of common management problems which we all face and need to be better prepared for.

To come:

- Dealing with the media $V O$ 'Loughlin

- How to appoint a senior house officer $H$ Guly

- How to conduct an SHO appraisal $M \mathcal{F}$ Clancy

- Organising training for undergraduates and SHOs

$N$ Rawlinson

- How to organise a higher training programme in $A \& E$

H Guly

- Managing a bed crisis $N$ Egan

- Time management $C$ McLauchlan
- Complaints-and how to deal with them G Bryce

- Risk management $H R$ Guly

- Purchasing new equipment $C D H$ Oakland

- Organising a medical conference $\mathcal{f}$ Wyatt

- Disciplinary procedures I P Stewart

- Choosing an A\&E department computer system $B C$ Elvin

- Dealing with the police $P A W H o w a r t h$ 